\title{
E-Learning and School Development - Strengths and Challenges of Capacity Building in School Development Projects
}

\author{
$\underline{\text { http://dx.doi.org/ijac.v4i3.1737 }}$ \\ Line Skov Hansen ${ }^{1}$ Anne-Karin Sunnevåg ${ }^{2}$ and Anne Kostø1 ${ }^{2}$ \\ ${ }^{1}$ University College Nordjylland, Nørresundby, Denmark \\ ${ }^{2}$ Hedmark Universtity College, Hamar, Norway
}

\begin{abstract}
This paper intends to focus on the strengths and challenges of capacity building in school development projects. The paper is based on practical experiences with three different projects CLL (Classroom Management, Learning and Teaching Authority) in Norway, the implementation of the LP- (learning environment and pedagogical analysis) model in Denmark as well as professional development of school administrators in a Danish municipality. The total number of participants in these projects is approximately 500 schools and 24000 teachers and school administrators. One of the challenges about school improvement in general, is linked to the development of competences and training of employees. Training of teachers and school administrators is often costly in terms of time, finances and organization. In accordance with these challenges, Centre of the Study of Educational Practice (SePU), Norway and Centre for Knowledge-Based Educational Practice (CVIPP), Denmark have designed projects for developing competences and training based on "blended learning" concepts. The didactic designs, in all three projects, are based on problem-oriented e-learning modules that are approached in teams. Through learning in teams, competences are developed together with colleagues. Through e-learning training and development of competences can take place at each school, within the limits and resources available at the school by using e-learning. Elearning can therefore contribute to improved flexibility in human resource development and lifelong learning.
\end{abstract}

Index Terms-blended learning, collaborative learning in teams, competence- and school development, e-learning.

\section{INTRODUCTION}

Additional education in Norway and Denmark has previously been carried out through training days at an educational institution, arranged for either single teachers or for all employees as a group. The individual teachers experience is that these days give them educational refill, which also has an effect on their teaching practice. Still, this effect does often not seem to contribute to the school's development in general. The training days that are meant for all employees give a common experience of education but has little effect on the school's development. This type of additional education is both time- and financially challenging a school's resources.

At Center of the Study of Educational Practice (SePU) Hedmark University College, Norway and Center for Knowledge-Based Educational Practice (CVIPP), University College Nordjylland, Denmark, e-learning are used for additional education and development of competences.
Common for the different types of professional development, is that they are all based on blended learning. Blended learning is defined as learning facilitated by the effective combination of different modes of delivery, models of teaching and styles of learning, and based on transparent communication amongst all parties involved with a course. The ongoing educational development in all three projects is not to be placed exclusively in an educational institution, but rather within the workplace. This offers an opportunity for development of competence among colleagues. All three projects are based on an understanding of learning as a process where you learn by collaborating with others.

This paper will focus on the strengths and challenges using ICT (information and computer technology) in professional and school development. The focus will mainly be on e-learning based on collaboration in teams. In all three projects e-learning is used as a tool to scaffold a learning process where teachers receive feed-back, knowledge-based texts, assignments, newsletters, videos and literature through e-mail or through a digital platform. Literature and assignments are to be processed and worked on in teams consisting of teachers teaching different subjects and grade levels. The teams hand in reports from their meetings to an external advisor who gives them feedback on the work. In the projects the technology has varied from more traditional and formal learning management systems to wikis (Web 2.0 technology).

The term "Web 2.0" is often used to describe the internet as we know it today. The term is to be seen in relation to the term "Web 1.0", and it is supposed to point out the development that has taken place over the last ten years from a static internet to a more dynamically interactive and social internet [1]. Dialogues, teamwork and production are terms often used to describe the essence of Web 2.0 [2]. A wiki is an example of Web 2.0 technology. A wiki is a network based communication- and collaboration tool that makes it possible for multiple users to produce content/knowledge. To edit or add content to a wiki is relatively easy. All you need is a computer with internet access. A wiki makes it possible to have network based collaboration. Collaboration within wikis is a different type of team work than using e-mails mailing the files between the participants [2][3]. Collaboration is to be distinguished from cooperation. In cooperation partners split the work, solve sub-tasks individually and then assemble the partial results into the final output. In collaboration partners do the work 'together'[4]. In the paper we present 
experiences from three different ongoing school development projects. These projects differ from each other in organization and content. Still, they all have the main aim of making practice-related competence development, where collaboration in teams and e-learning plays a central part.

We point out that this paper is based on our experiences, and is not a result of research based evaluations of this type of work. This is because the projects are still in process.

\section{PRESENTATION OF THREE DiFFERENT DEVElOPING PROJECTS}

\section{A. The LP-model, Learning Environment and Pedagogical Analysis}

The LP-model (Learning Environment and Pedagogical Analysis) is a school comprehensive research- and development process where all teachers and administrators in a school are included [5]. The LP-model has, from 2007 until today, been implemented in 522 schools in Denmark, and include more than 200.000 students and 27000 teachers [6]. CVIPP is responsible for the implementation of the LP-model in Danish schools, while SePU and DPU (Danish School of Education), University of Århus are responsible for researching the process. The intention of the LP-model is to give schools an explicit understanding of the features that triggers, affects and support behavioral- and learning difficulties in schools, and to develop helpful pedagogical efforts to alleviate these challenges. The teachers work in teams with a pedagogical analysis model which they use systematically to approach the challenges at hand. The teachers receive external supervision, and specific training is prepared to increase the teachers, leaders and supervisors competence based on a blended learning perspective with a strict focus on elearning.

\section{B. CLL, Classroom Management, Learning and Teaching Authority}

CLL (Classroom Management, Learning and Teaching Authority) is a school comprehensive research- and development project, carried out over three years where the aim is to decrease the drop-out-rate and increase the learning outcomes in secondary schools within both academic- and vocational programs. CLL also focuses on developing the teachers' authority through increasing their knowledge of class leadership and teaching [7]. It also focuses on the teachers social relations to their students [8], [9]. The project is ongoing in 7 secondary schools in Norway, and consists of approximately 600 participants. SePU is responsible for the research and for the educational content of the project and Hedmark County Council, as the school owner, is responsible for the implementation. The teachers in CLL are collaborating in groups with colleagues teaching different subjects, and the work is done mainly through blended learning. E-learning, communication, education, sharing experiences, supervision and observation of the teaching process are all important components in relation to the e-learning platform.

\section{School Administrator Education in a Danish Municipality}

In Denmark, all school leaders in a municipality participate in a $1 \frac{1}{2}$ year professional development further pro- gram. The program is developed and carried out by CVIPP. The purpose of this education is "Leading alteration processes within a systematical context". This competency development of the municipality`s school administrators will secure and strengthen a successful implementation of the LP-model in the schools, and keep the intensity of the work up. Furthermore the goal is to equip participants with competencies to function as soundingboards for teachers and pedagogues for developing systematic thinking and the ability to handle resistance to progress. Besides this, related to the project, it is also a goal to create a common basis for work and collaboration among various schools and school administrations within the municipality. The professional development program is based on blended learning, and varies between lectures, assignments, e-learning, dialogue and practice. The participants work in teams throughout the whole program. The participants attend two retreats and one daylong course. In between these three planned events, participants work together in teams on the given assignments. The curriculum has been focused on including wikis as a new technology to contribute, communicate, and collaborate when learning together in teams. The professional development program does not end with an exam. Instead, the participants publish a book where the teams contribute with articles about different themes related to school administration.

\section{ICT-SUPPORTED ADDITIONAL EDUCATION}

\section{A. Use of e-learning in LP and CLL}

Implementation of both the LP-model and CLL, entail e-learning to increase competency of the employees. In both projects the teachers are divided into teams across previously established teams, who meet 1-2 hours every other week. Each team has a facilitator who has received training or education through e-learning in facilitating a team. The main education of all employees is organized into e-learning modules, and consists of texts and assignments. Within some of the modules, videos are available. In every team meeting the participants study texts or watch videos before they complete assignments with knowledge related to their own practice. At the next group meeting, the procedure is repeated. They also work together on feedback given on the last module by their advisor. The e-learning platform consists of different rooms within an online learning platform. There are rooms where text material and assignments are placed, and where the participants upload their replies. The advisor and participants are able to communicate through the platform. Feedback from the external advisors is also placed in the room.

\section{B. Use of wikis in professional development for school administrators}

The additional education for school leaders is a new education that is carried out as a pilot project. The education is divided into two modules: Module 1 is based on giving the participants new theoretical knowledge. This module in many ways resembles the LP- and CLL modules. The 2nd module use wikis (Wikispaces) as a platform for the participants distributive authorship when producing articles. Wikis make it possible to create a userfriendly and low-cost learning environment that gives the participants the opportunity to share knowledge, brainstorm and collaborate over the internet in a way that the e- 
learning platform normally used by CVIPP, does not offer. Through collaboration in teams consisting of 4-6 participants who write scientific articles using the knowledge they obtained during module 1 . The topics of the articles are defined by each team based on the team members' experiences from different work situations. During module 2 the teams are created based on the participants' interests rather than on which school they belong to. Each team would receive guidance from a journalist and an associate professor in pedagogy during the writing process. These advisors bring feedback to the process based on the content and structure of the articles.

This project consisted of 17 teams, each given their own wiki. The teams were able to make new pages, add content, edit and communicate with each other through the wiki. The wiki was set to send participants a notification by e-mail, every time something was edited or added to their space. The wiki history-function saved all previous drafts of the document, which gave the participants the opportunity to edit and add content to their documents as they wished. Besides the collaboration through wikis, the team members also used e-mails, and they had multiple face-to-face meetings. The teams also received one faceto-face feedback in addition to the feedback they were given on e-mail. The advisors had access to all 17 wikis, and to an "administrator-wiki" which made it possible for the advisors to overlook the work process within all 17 wikis. All 17 wikis were attached to a common platform with a common space available for all participants and advisors. In the common space there was a bulletin board, and access to different resources like literature, videos, calendar, lecture slides and information about the project. Wherever possible, Web 2.0 tools were used to distribute these different resources (Vimeo, Issuu, Google Calendar).

\section{STRENGTHS AND CHALLENGES IN ICT-SUPPORTED LEARNING AND TEAM WORK}

\section{A. Learning and Working Together in Teams}

In both Denmark and Norway, within the primary schools, a demand towards collaborative learning in teams has developed. Collaboration in teams could be viewed as the organizational answer to a number of pedagogical and scientific challenges that the schools are facing. Within the already presented professional development program, the team is central to fulfilling the learning and development demands that are given to both the individual participant and to the school. The experience from all three projects is that teamwork does not work by itself; it has to be learned and facilitated. Learning do the work in teams is also about being aware of yourself and how you work and react in collaboration with others. Teamwork can thereby also be a personal development process for each member and for some participants it can be a new and challenging situation [10].

Within the three projects presented earlier, one of the strengths of placing the teachers in teams when they work with education and increasing competency through the elearning modules is that it develops both the scientific community, and also the social community. The participants generally benefit from working in teams with others who have different scientific knowledge, who teach different grade levels and who work in different schools. They make time during their busy schedule, to discuss, reflect and work together to find solutions that can be used on pedagogical challenges they may experience in their work environment. Discussing pedagogic and their own experiences help them be aware of their own values as teachers. This can be both challenging, and a strength when participants don't know or are used to work with each other. The collaboration and the face-to-face communication in group meetings develop a common language and a common foundation for work for the teachers. These are important sources for solidarity, and it seems like the teachers all in all experiences this as very meaningful.

Michael Fullan claims that "educational change depends on what teachers do and think - it's as simple and as complex as that" [11]. This means that changing the practice does not only require that the teachers change the content and their way of lecturing, but it also requires a change in their pedagogical understanding and experience. We have found that working in teams and reflecting on difficulties together with others, and connecting these reflections to theory and empirical studies, contributes to a cultural development in each school. The teachers come across as having shared understanding, attitudes and practice, and with a common wish to maximize the students' potential for learning. Less "private practices" is seen in schools participating in these development projects.

In CLL project in secondary schools, results show that participants to a greater extent show resistance to both teamwork and to work with new pedagogical literature and receive advising etc. The complexity in the secondary education differs from that in primary education in many ways. Larger administrative groups, larger differences between the educational programs, both within subject matters, lecture methods and numbers of students, and the teachers have very different educational backgrounds and competencies. Within the same team there may be both highly educated teachers with academic background and subject teachers with practical or vocational educational background. It is natural to think that the academically educated teacher and the craftsman who teaches a subject matter have different understandings of pedagogy, and that they have very different work situations. In addition to challenges according to the teachers' pedagogical understanding, and their understanding of their own teacher role, this complexity brings new challenges to the table.

There is little experience starting large development projects including the whole school in secondary education. Teachers have basically been left alone with their teaching, and it has been what we call privatized in a much larger scale than it is in primary education. In CLL teachers are supposed to work together across subject matters and educational programs, they are supposed to use e-learning tools, and they are supposed to reflect together in matters of pedagogical topics such as class leadership, relations with students, encouragement, feedback to the students etc. This seems to create resistance within the teacher groups. When change is combined with the teachers' foundational values, and their experiences are questioned, their autonomy becomes challenged. In CLL the theoretical content is based on what research claims give the best learning outcome for students, and this is what teachers are supposed to have in mind when they discuss the e-learning modules related to their own practice. Thereby the teachers' autonomy should to a much more large extent be based on the liberty to choose be- 
tween what research presently indicates produce the best results for all students. This seems to be one of the main challenges of this project.

In the project for school administrators the participants generally benefit both from the e-learning and especially from the collaboration in teams. In module 2 the mixed teams across schools were at first hand not welcomed by all participants. "Why not just work with people we know"? Through the process this resistance changed. The participants experienced that the collaboration about the article brought new reflections and perspectives to practice and that working in mixed teams across schools gave new professional connections and relations. In module 2 the supervisors give feed-back on the written text and help the teams with literature for their chosen subject. This ongoing process is a challenge in terms of time pressure and the theoretical level as well as the ambitions about the final product which both advisors and teams can have. School administrators in Denmark have many demanding tasks and a busy schedule to deal with. It can be a challenge for these participants is to find the time for studying and for collaboration.

\section{B. E-learning and development of competences}

Training teachers is costly both in terms of time and finances. The use of e-learning in development of competences can save both time and money for the school. This makes it possible to collectively increase teachers' competence. Time is scheduled in the teachers ' work agreement for professional development every week throughout the year. This time is to be used for education and developing competencies related to projects, without making it yet another tasks, teachers have to pay attention to in their already busy schedule. According to implementation research, working systematically with something over time has a much greater possibility of producing a successful result [11].

However, we also experience challenges when starting development projects in schools where teachers are expected to collaborate in teams, and receive their education through e-learning. For many it is challenging using technology to develop competence and collaborate with others. Individuals have different ways of working with challenges [12]. Some participants do not feel confident enough to communicate and collaborate with others through an e-learning platform or a wiki. Some have insecurities towards using new ICT-tools because of their lack of technological competence. Both teachers and school administrators may find it difficult to admit their shortcomings to their group because of the lack of confidence, especially at the beginning of the process. However, using new technology as a group may contribute to a collaboration that increases confidence towards the use of technology. It may also help participants obtain knowledge about new ICT- tools that are to be used in other situations later on.

In all three projects, there are some variation in the loyalty level towards working with the e-learning modules literature and assignments. This might have something to do with to what extent participants experience correlation between the content of the e-learning modules and their own need for developing competence. Within all three projects, both oral and written knowledge matters. It is important to be aware of the variation between the participants` preferences within these areas. This makes it chal- lenging to establish collaboration in terms of expectations and strengths/weaknesses independent of whether the collaboration is net- based or face-to-face.

We experience challenges with the fact that some schools expect tailor made programs to be presented on the e-learning platform, and that these programs will be a perfect match to any grade level or department. A perfect match is neither possible nor desirable. Every grade level, every teacher or school administrator is different, and has different needs, and the program needs to be adjusted to the users. Within the e-learning platform used in CCL and in the wikis used for the professional development of school administrators it is possible for the participants to take part in developing their own tools using the knowledge given through the e-learning module. It is also possible to share knowledge and experiences within these digital platforms. Teachers, administrator and schools use these options in various manners.

In the professional development of school administrators, the 17 teams only used the wiki in the brainstorming phase of the writing process. As groups found a need to place their texts into Microsoft Word, they left the wiki and started e-mailing or meeting face-to-face instead. Collaboration with wikis was a challenge not only for the participants, but also for the advisors. The advisors also preferred e-mail correspondence rather than communicating directly through the wiki. It also appeared that not all settings in the wiki were adjusted to be as helpful as possible.

\section{SUMMARY AND CONCLUSION}

Working on these projects has given us valuable knowledge in relation to professional development of school administrators, and carrying out extensive development projects at different schools. This paper intended to focus on education and development of competence through e-learning in teams. We summarize our experiences as follows:

- Collaboration in teams initiated in text and assignments through e-learning modules is especially experienced as challenging in the beginning. It takes some time to establish confidence within the team. When confidence is established, most participants express that it is an enriching way of working where experiences are exchanged, and where the possibility of developing their own competence is present.

- Collaboration in teams contributes in developing a common language, common attitudes and common practice. It also contributes to develop the teachers` own practice, and the schools`culture.

- The advisor plays a challenging role in terms of being a planner, a facilitator, a dialogue partner and an expert at the same time.

- Facilitation, support and planning of the work are all of great importance to the participants' willingness and loyalty to work both in teams and with the assignments from the e-learning modules on the digital platform.

- The use of ICT-tools like wikis or an e-learning platform when working with literature and assignments has been challenging for some participants, and the intended ways of use have varied. 
- Web 2.0 technologies demands Web 2.0 pedagogic and didactic [13] : Collaborating through wikis requires both that the participants learn the functionalities and how to collaborate both synchronically (realtime) and not synchronically over the internet.

Both use and work with e-learning in professional development may contribute to create new and flexible ways of lecturing and presence. This may change and expand the ability to work with competency development, and it presents new opportunities to work towards a common construction, a common reflection and to receive feedback based on practice-oriented knowledge. The didactic design should aim to make a collaborative learning environment that present the opportunity to gather information, to produce knowledge, either in groups or individually. To establish this type of learning environment, it is important to establish facilities, develop resources that may support different ways of learning as well as different working processes.

From all three projects we may draw the conclusion that the ICT-tool itself makes no change by itself. The most important change lies within the participants, both teachers and advisors. All three projects are based on an understanding of learning as a process where you learn by collaborating with others. It is an important part in all the three competency developing processes that the participants' problems and assignments are anchored in known practice. Problem-oriented learning does not only focus on motivating the participants, but is also of significant actuality and relevance to the place of work. In relation to this aspect, there are three guidelines that stand out within the didactic designs:

- The team construct their knowledge collaboratively

- They work with a mutual commitment

- The teams are working towards a common goal

The applied technology used for e-learning in all three projects should accomplish these three guidelines. To succeed with this is not something that happens right away, but something that will, together with planning and execution of the projects, have to be evaluated and revised on an ongoing basis.

\section{REFERENCES}

[1] N. Dohn, "Teaching with wikis and blogs: Potentials and pitfalls", Proceedings of the 7th International Conference on Networked Learning 2010. http://www.lancs.ac.uk/fss/organisations/netlc/ past/nlc2010/abstracts/PDFs/Dohn.pdf

[2] B. Alexander, "Web 2.0, A new wave for Innovation for Teaching and Learning?" EDUCAUSE Review, vol. 41, no. 2 (March/April 2006), pp. 32-44.

[3] J. Chao, "Student project collaboration using wiki", Proceedings of the 20th Conference on Software Engineering Education and Training (CSEE\&T 2007), Dublin, Ireland: July 3-5, 2007

[4] P. Dillenbourg, "What do you mean by "collaborative learning "?" In P. Dillenbourg (Ed.), Collaborative learning: Cognitive and computational approaches New York: Elsevier Science Ltd, 1999, pp. 1-16.

[5] T. Nordahl, T, "Laringsmiljф og pedagogisk analyse. En beskrivelse og evaluering av LP-modellen”. NOVA rapport 19/05 2005. Oslo: Norsk institut for forskning om oppvekst, velferd og aldring.

[6] http://www.lp-modellen.dk/

[7] L. Qvortrup, "Læreren må bli best i det han skal være best i", Bedre skole vol. 3/2009 pp.. $76-82$.
[8] K. E, O'Connor, "You choose to care": Teachers, emotions and professional identity. Teaching \& Teacher Education, 2008, vol. 24 , no. 1 , pp. 117-126. http://www.nebrija.com/encuentrocalidad/documentos/teachers\%20emotions.pdf, http://dx.doi.org/10.1016/j.tate.2006.11.008

[9] J. Cornelius-White, "Learner-Centered Teacher-Student Relationships Are Effective: A Meta-Analysis”. Review of Educational Research, 2007, vol. 77 no.1, pp.113-143. http://dx.doi.org/10.3102/003465430298563

[10] M. Herløv Petersen, "De larende lcerere: skole og kvalitetsydvikling I det modern samfund". Kroghs forlag A/S.

[11] M. G. Fullan, "Leading in a culture of change", San Francisco: Jossey-Bass, 2001.

[12] E. M. Rogers, “Diffusion of Innovations”. New York: The Free Press, 1995

[13] K. Gynther, “Didaktik 2.0: lcerermiddelkultur mellem tradition og innovation. Akademisk Forlag, 2010.

\section{AUTHORS}

Line Skov Hansen, Master in ICT and Learning, project manager at the Centre for Knowledge-Based Educational Practice (CVIPP), University College Nordjylland, Lindholm Brygge 35, 9400 Nørresundby, Denmark (lsa@ucn.dk).

Anne-Karin Sunnevåg, Master in Pedagogic, associate professor at the Centre of the Study of Educational Practice (SePU), Hedmark University College, Skolagata 12, Hamar, Norway (annekarin.sunnevag@hihm.no).

Anne Kostøl, Master in Special Education, associate professor at the Centre of the Study of Educational Practice (SePU), Hedmark Universtity College, Skolagata 12, Hamar, Norway (anne.kostol@hihm.no).

\section{ACKNOWLEDGMENT}

The authors would like to thank Karoline Sunnevåg Madsbu for the first English translation and Lilli H. Jensen, Assistant Director, International Student Services, Rochester Institute of Technology for the final English translation

This article is an extended version of a presentation at ICELW 2011 The International Conference on E-learning in the Workplace, held from June 8th-10th, 2011 at Columbia University, New York, NY, USA. Submitted, July 4th, 2011. Published as resubmitted by the authors August 8th, 2011. 